The Israeli Journal of Aquaculture - Bamidgeh, IJA_69.2017.1379, 5 pages

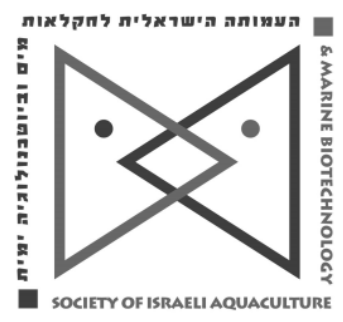

The IJA appears exclusively as a peer-reviewed on-line open-access journal at http://www.siamb.org.il. To read papers free of charge, please register online at registration form.

Sale of $I J A$ papers is strictly forbidden.

Short communication

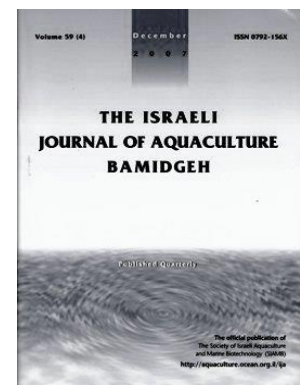

\title{
Feeding Depths of Wild Caught Yellowfin Tuna Thunnus albacores Juveniles and Skipjack Tuna Katsuwonus pelamis in Sea Cages
}

\author{
Zhenhua $\mathrm{Ma}^{1,3,4}$, Shaosen Wu ${ }^{2,3,4}$, Xiangjun Meng ${ }^{5}$, Gang $\mathrm{Yu}^{1,3,4}$, \\ Qia'er $\mathbf{W u}^{2}, 3,4 * *$
}
${ }^{1}$ Tropical Aquaculture Research and Development Centre, South China Sea Fisheries Research Institute, Chinese Academy of Fishery Sciences, Sanya 572018, P.R. China

2 South China Sea Fisheries Centre, South China Sea Fisheries Research Institute, Chinese Academy of Fishery Sciences, Guangzhou 510300, P.R. China

${ }^{3}$ Key Laboratory of Offshore Fishery Development, Ministry of Agriculture, Guangzhou, 510300, P.R. China

${ }^{4}$ Key Laboratory of South China Sea Fishery Resources Exploitation and Utilization, Ministry of Agriculture, Guangzhou, 510300, P.R. China

5 Sansha Meiji Fishery Developments Pty Ltd., Haikou 570100, China

Keywords: Feeding; growth and survival; yellowfin tuna Thunnus albacares; skipjack tuna Katsuwonus pelamis.

\begin{abstract}
This study was conducted in the lagoon of Mischief Reef, South China Sea to test the feasibility of feeding and rearing wild caught yellowfin tuna Thunnus albacares and skipjack tuna Katsuwonus pelamis juveniles in small, deep seawater, cages. Fish started active feeding four days after transfer to the rearing cage. Initial feeding depth between yellowfin tuna and skipjack tuna was not significantly different $(P>0.05)$. The initial feeding depth for yellowfin tuna juveniles was $2.97 \pm 1.09 \mathrm{~m}$, and skipjack tuna fed at $2.95 \pm$ $0.77 \mathrm{~m}$. After the 30 day rearing experiment specific growth rates of yellowfin tuna and skipjack tuna were: $0.25 \pm 0.02 \% /$ day and $0.32 \pm 0.03 \% /$ day, respectively; survival rate of yellowfin tuna was $100 \%$, and the survival rate of skipjack tuna was $82.6 \%$. The estimated feed conversion ratio was 9.73 in this study. The results of this study provide practical data for culturing wild caught yellowfin tuna and skipjack tuna juveniles in sea cages.
\end{abstract}

* Corresponding author. Tel.:+86 0898-83361232, fax: +86 020-84451442, e-mail: zhenhua.ma@hotmail.com \& wqe66@163.com 


\section{Introduction}

The yellowfin tuna Thunnus albacares is an important fish species worldwide. Recent studies indicate that yellowfin tuna are caught between the eastern and western boundaries of the Pacific Ocean (Schaefer et al., 2011). The skipjack tuna Katsuwonus pelamis is one of the major fishery species in South China Sea (Ma et al., 2016). Due to global environment changes and human intervention, stocks of commercial fish of these two species have dropped dramatically. Therefore artificial rearing of these species to a commercial size is an alternative way to support the growing market demands. Although several attempts have been made to artificially breed these two species (Ashida and Horie, 2015; Wexler et al., 2003), fingerling supply of these species is still largely dependent on fish caught in the wild.

In nature, tuna have developed the ability to physiologically thermo-regulate their body temperature to pursue prey from the surface temperature, mixed layer into deeper, colder water and return to the surface (Block et al., 1997; Dagorn et al., 2000; Holland et al., 1992). Acclimation and rearing success of these wild caught juveniles depend therefore on the understanding of their feeding behavior and proper feeding management (Gordin, 2003). However, related information on these studied species is rare. The present study was designed to explore the feeding behavior of yellowfin tuna and skipjack tuna juvenile, and aimed to develop a proper acclimation and rearing methods.

\section{Materials and Methods}

This study was conducted in the lagoon of Mischief Reef, South China Sea (Fig.1) between May and June 2016. Wild yellowfin tuna and skipjack tuna juveniles were captured in the open sea of Mischief Reef $\left(9^{\circ} 51^{\prime} 44^{\prime \prime} \mathrm{N}, 115^{\circ} 30^{\prime} 56^{\prime \prime} \mathrm{E}\right.$, Fig. 1) using lightfalling net method, and transported back to the lagoon of Mischief Reef in a sea cage. Upon arrival at the lagoon, fish were held in the transporting cage for two days before transferring them in two steel structures $(6.5 \times 6.5 \times 5 \mathrm{~m})$, a total of 12 yellowfin tuna (29.98 $\pm 8.78 \mathrm{~cm}$, total length) and 23 skipjack tuna $(29.39 \pm 7.35 \mathrm{~cm}$, total length). After transfer they were deprived of food for three days until the beginning of the experiment. During the 30 day experimental period, water temperature was $31.41 \pm 0.30$ ${ }^{\circ} \mathrm{C}$, and current velocity was $0.25 \pm 0.12 \mathrm{~m} / \mathrm{s}$.

Fish were fed chopped frozen Euthynnus yaito meat $(3 \times 2 \mathrm{~cm})$ once a day at 0700 am. The chopped $E$. yaito meat was mixed with aquaculture grade antibiotics and mixed vitamins during the first two weeks of the feeding trial. After this, frozen $E$. yaito meat was chopped and fed directly to fish until the completion of the experiment. The nutritional composition of experimental feed was as follows: $23.45 \pm 0.48 \%$ protein, $1.46 \pm 0.42 \%$ crude fat, $1.38 \pm 0.07 \%$ ash, and $72.27 \pm 1.58 \%$ moisture. The fish were fed to satiation and feed was weighed before and after feeding to calculate the feed conversion ratio (FCR).

Three GoPro4 $®$ cameras were used to record feeding activity, growth, survival, and health condition of fish on each day. Adobe Photo Shop CS3 was used to perform the image analysis. Growth was determined by specific growth rate (SGR) in \% per day using the following equation (Hopkins, 1992):

SGR $=100(\operatorname{InSLf}-\operatorname{InSLi}) / \Delta \mathrm{t}$, where SLf and SLi were the final and initial fish total length $(\mathrm{cm})$, respectively, and $\Delta \mathrm{t}$ was the time between sampling days.

Fish weight was estimated by length-weight relationships of yellowfin tuna and skipjack tuna as reported by Ma et al. (2016): W-yellowfin $=0.0096 \times \mathrm{L}^{2.548}$ and $\mathrm{W}$ skipjack $=2.7593 \times \mathrm{L}^{1.4437}, \mathrm{~W}$-yellowfin and $\mathrm{W}$-skipjack were the estimated wet weight of yellowfin tuna and skipjack tuna; $L$ was measured fish length. Coefficients of variation $(\mathrm{CV}, \%)$ of fish length was calculated from standard deviation and the mean for each species at the end of this study ( $\mathrm{CV}=100 \times \mathrm{SD} / \mathrm{mean})$. Independent T-test was used to compare the feeding depth and growth between yellowfin tuna and skipjack tuna juveniles via SPSS 18.0. 
To prevent injured skin infection, aquaculture grade antibiotics and mixed vitamins were added to fish diet in the first two weeks of the feeding trial. After two weeks of continuous feeding of antibiotics and vitamins treated diets, the appearance of injures disappeared in fish skin.

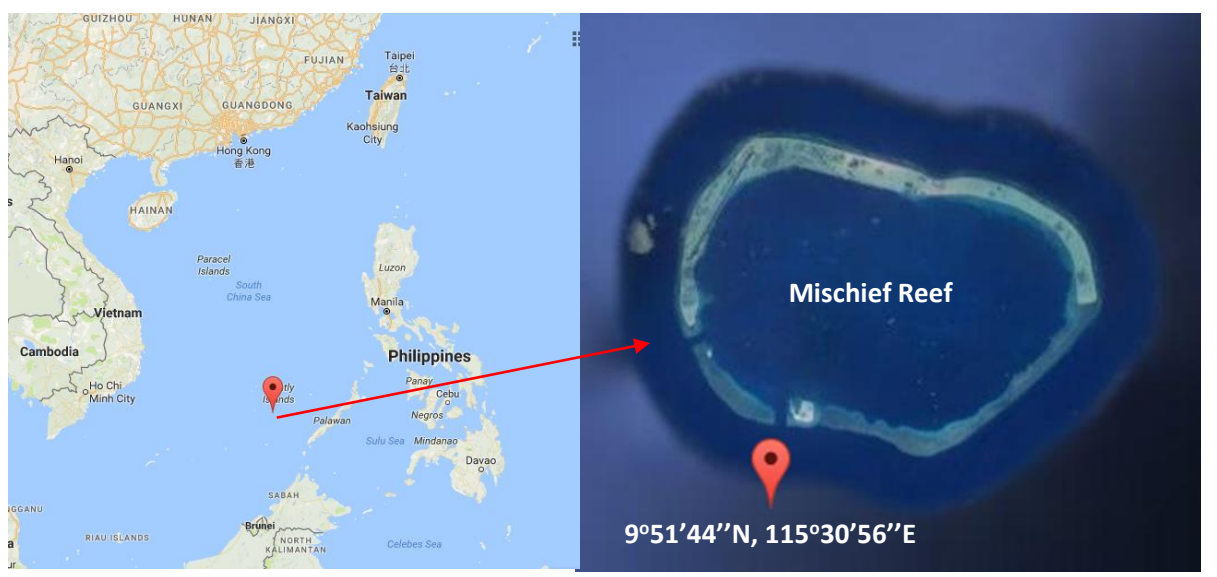

Fig. 1 Map of Mischief Reef and fish capture location in South China Sea

\section{Results}

Initially, when feeds were first distributed to the fish, the active feeding depth was $2.95 \pm 0.77 \mathrm{~m}$ (Fig. 2) and was not significantly different between two species $(P>0.05$, Fig. 2). On the second day, the active feeding depth of yellowfin tuna and Skipjack tuna was $2.28 \pm 0.85 \mathrm{~m}$ and $2.25 \pm 0.77 \mathrm{~m}$, respectively. On the eighth day fish of the two species started to feed on the water surface and continued to do so throughout the experiment $(P>0.05)$, (Fig. 2). To the best of our knowledge, this is the first report on the active feeding depth of wild caught yellowfin tuna and skipjack tuna juveniles in confined conditions.

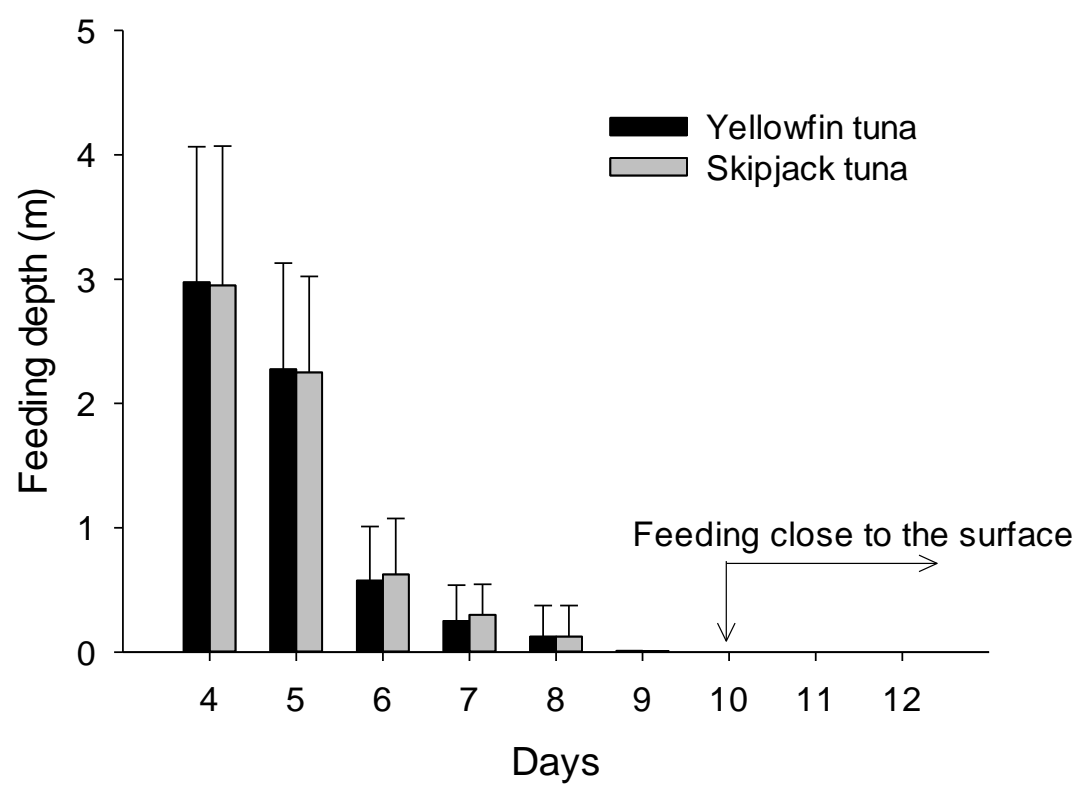

Fig. 2 Active feeding depth of yellowfin tuna Thunnus albacares and skipjack tuna Katsuwonus pelamis juveniles

In this study, the specific growth rate (SGR) of yellowfin tuna was $0.25 \pm 0.02$ $\%$ /day, which was significantly lower than the SGR observed in skipjack tuna which was $0.32 \pm 0.03 \% /$ day, $\mathrm{P}<0.05$, (Table 1 ). Upon completion of the experiment, the CV of yellowfin tuna and skipjack tuna was 5.55 and 5.02, respectively. 
Survival rates of the yellowfin tuna and skipjack tuna were $100 \%$ and $82.6 \%$ respectively (Table 1 ). In skipjack tuna, four fish died in the first week during the acclimation period probably due to skin infection injuries that occurred during their capture after which they recovered completely.

Table 1. Specific growth rate (SGR), co-efficient variation, and survival rate of wild caught yellowfin tuna Thunnus albacares and skipjack tuna Katsuwonus pelamis juveniles

\begin{tabular}{llll}
\hline & SGR (\%/day) & CV & $\begin{array}{l}\text { Survival } \\
(\%)\end{array}$ \\
\hline Yellowfin tuna & $0.25 \pm 0.02$ & 5.55 & $100 \%$ \\
Skipjack tuna & $0.32 \pm 0.03$ & 5.02 & $82.6 \%$ \\
\hline
\end{tabular}

\section{Discussion}

In nature the feeding depth of tuna varies dramatically while in artificial rearing conditions, tuna are restricted to a constant depth and fed with a single type of feed. These conditions may have affected their feeding behavior.

In this study, the SGRs of yellowfin tuna and skipjack tuna were $0.25 \pm 0.02$ and $0.32 \pm 0.03 \%$ /day, respectively. Although several documents have described the growth of yellowfin tuna (Fonteneau and Chassot, 2013; Kikkawa and Cushing, 2002) and skipjack tuna (Andrade and Kinas, 2003; Hallier and Gaertner, 2006), most of these publications relate to tests conducted under natural conditions, and were based on the age-growth in adult fish. Growth-related information of yellowfin tuna and skipjack tuna in constrained conditions is rare. To the best of our knowledge, this is the first data on the juvenile growth of these species under artificial rearing condition.

Results from the present study suggest that feeding habits of yellowfin tuna and skipjack tuna can be adapted to relatively small size sea cages. Results also suggest that a high skin self-healing process exists in these two species. This accelerated healing may warrant further investigation. In order to conduct commercial scale aquaculture practices, future research should aim to improve the method of capturing tuna juveniles and understanding the nutrition requirements for these two species.

\section{Acknowledgements}

This study was supported by Ministry of Agriculture of China Special Financial Funding for Nansha Fisheries Management (South China Sea Fisheries Centre). The authors would like to thank Captain Shuliang Wu and Yueqing Huang, and all the crew members from fishery vessel "Qiong'le'dong 11201" for their professional skill in conducting the fish catching, and Mr. Yan Liu and Zhijian Cheng for their collaboration during data collection.

\section{References}

Andrade, H. A. and Kinas, P. G. 2003. Growth models for the skipjack tuna (Katsuwonus pelamis) caught in the Southeastern coast of South America. Col. Vol. Sci. Pap. - ICCAT, 55 (5):1916-1925.

Ashida, H. and Horie, M. 2015. Reproductive condition, spawning season, batch fecundity and spawning fraction of skipjack tuna Katsuwonus pelamis caught around Amami-Oshima, Kagoshima, Japan. Fish. Sci., 81 (5):861-869.

Block, B. A., Keen, J. E., Castillo, B., Dewar, H., Freund, E. V., Marcinek, D. J., Brill, R. W. and Farwell, C. 1997. Environmental preferences of yellowfin tuna (Thunnus albacares) at the northern extent of its range. Mar. Biol., 130: 119-132.

Dagorn, L., Bach, P. and Josse, E. 2000. Movement patterns of large bigeye tuna (Thunnus obesus) in the open ocean, determined using ultrasonic telemetry. Mar. Biol., 136:361-371. 
Fonteneau, A. and Chassot, E. 2013. An overview of yellowfin tuna growth in the Atlantic Ocean: von bertalanffy or multistanza growth? Collect. Vol. Sci. Pap. ICCAT, 69 (5):2059-2075.

Hallier, J. P. and Gaertner, D. 2006. Estimated growth rate of the skipjack tuna (Katsuwonus Pelamis) from tagging surveys conducted in the Senegalese area (19961999) within a meta-analysis framework. Col. Vol. Sci. Pap. - ICCAT, 59 (2):411-420.

Holland, K., Brill, R., Chang, R., Sibert, J. and Fournier, D. 1992. Physiological and behavioral thermoregulation in bigeye tuna (Thunnus obesus). Nature, 358: 410-411.

Hopkins, K. D. 1992. Reporting fish growth: a review of the basics. J. World Aquacult. Soc., 23: 173-179.

Gordin H., 2003. Mariculture in Israel. The Israeli Journal of Aquaculture - Bamidgeh 55(4), 219-221.

Kikkawa, B. S. and Cushing, J. W. 2002. Growth of yellowfin tuna (Thunnus albacares) in the equatorial western Pacific Ocean. The 15 th Meeting of the Standing Committee on Tuna and Billfish, Honolulu, Hawaii, p. 22-27.

Ma, Z., Yu, G., Wu, Q., Ma, S., Wu, S. and Chen, X. 2016. Length-weight relationships of yellowfin tuna Thunnus Albacares, skijack tuna Katsuwonus Pelamis, yaito tuna Euthynnus Taito, and blue round scade Decapterus Maruadsi from Mischief Reef, South China Sea. Int. J Inn. Stu. Aqua. Biol. Fish., 2 (4):27-30.

Schaefer, K. M., Fuller, D. W. and Block, B. A. 2011. Movements, behavior, and habitat utilization of yellowfin tuna (Thunnus albacares) in the Pacific Ocean off Baja California, Mexico, determined from archival tag data analyses, including unscented Kalman filtering. Fish. Res., 112:22-37.

Wexler, J. B., Scholey, V. P., Olson, R. J., Margulies, D., Nakazawa, A. and Suter, J. M. 2003. Tank culture of yellowfin tuna, Thunnus albacares: developing a spawning population for research purposes. Aquaculture, 220:327-353. 